\title{
Space Law (2020)
}

\author{
Diego Zannoni*
}

This practice report describes and assesses disaster law related developments and initiatives involving outer space. The focus will be on three distinct but connected issues: the use of outer space for the prevention and management of disasters on Earth, with a special focus on pandemic outbreaks; outer space as the place where disasters may occur due to the increasing congestion of orbits around Earth with space debris; and outer space as a potential source of disaster, i.e. the threat posed by asteroids crossing Earth's trajectory. This analysis will focus on the activities of the United Nations Committee on the Peaceful Uses of Outer Space (CoPUos), which in its annual reports consistently addresses these three issues.

A cautionary note, before starting with the analysis. Owing to the difficulties imposed by the coronavirus disease pandemic, both the copuos Legal Subcommittee and the Committee agreed to cancel their sessions. This means that only the copuos Scientific and Technical Subcommittee issued a report in 2020. The COPUOS Legal Subcommittee and the Committee essentially took decisions and actions aimed at ensuring the continuity of their activities from 2019 .

\section{The Use of Outer Space for Disaster Prevention and Management}

One item in the annual copuos Scientific and Technical Subcommittee agenda is: 'Space-system-based disaster management support'. The 2020 Scientific and Technical Subcommittee Report emphasizes the importance of ongoing activities to increase the availability and use of space-based solutions in support of disaster management, ${ }^{1}$ namely the International Charter on

\footnotetext{
* Researcher in International and European Union Law, University of Padua.

12020 Scientific and Technical Subcommittee Report (19 February 2020), UN Doc A/AC.105/ 1224, para. 119 .
} 
Space and Major Disasters, ${ }^{2}$ the Sentinel Asia initiative, ${ }^{3}$ and the Copernicus Emergency Management Service. ${ }^{4}$ The already identified trend ${ }^{5}$ is to support and strengthen the systems already in place, rather than create new ones. ${ }^{6}$ The multiplication of systems and the ensuing fragmentation could otherwise lead to difficulties in coordination in a sector where interoperability and multilateralism are essential.

Within the copuos Scientific and Technical Subcommittee, Member States' technical presentations focus on the scientific and technical developments they have achieved in the exploration and use of outer space. Far from being a sort of useless self-celebration, these presentations are important for exchanging good practices, and informing other Member States about ongoing or planned activities that other States may be able to participate in either as a contributor or as a user. ${ }^{7}$ The 2020 Report devotes particular attention to satellite-based augmentation systems which improve positional, navigational and timing performance of radio-navigation systems and provide important services in the context of disasters, for instance, error corrections and a short messaging service. ${ }^{8}$

2 The International Charter on Space and Major Disasters is a worldwide collaboration among space agencies, through which satellite-derived information and products are made available to support disaster response efforts. The Charter has been operational since November 2000. The text is available at <https://disasterscharter.org/web/guest/text-of-the-charter> last accessed (as any subsequent URL) on 1 May 2021.

3 For the Sentinel Asia initiative, see Terms of Reference on the Joint Project Team for Sentinel Asia Step-3, available at $<\mathrm{https}$ ///sentinel-asia.org/e-learning/Documents/Terms\%20of\%2O Reference\%2ofor\%2oSA\%2oStep3.pdf>.

4 See, Regulation (EU) 377/2014 establishing the Copernicus Programme [2014] oJ L 122; and Commission Delegated Regulation (EU) 1159/2013 supplementing Regulation (EU) No 911/2010 of the European Parliament and of the Council on the European Earth monitoring programme (GMES) by establishing registration and licensing conditions for GMES users and defining criteria for restricting access to GMES dedicated data and GMES service information [2013] oJ L 309 .

5 See the 'Space Law (2019)' IDL in Practice Section of this Yearbook.

6 Eswatini, Ghana and Tunisia had become members of the Charter and Costa Rica, South Africa, Viet Nam and Zimbabwe are in the process of becoming authorized users.

7 On technical presentations, see Governance and method of work of the Committee on the Peaceful Uses of Outer Space and its subsidiary bodies. Note by the Secretariat, UN Doc A/AC.105/C.1/L.384, section II, para. 4.

82020 Scientific and Technical Subcommittee Report, (n 1), paras. 147-15o. 
There is a significant nexus between disasters and health..$^{9}$ Because disasters have direct health impacts (mortality, morbidity and psychological trauma), as well as long-term impacts (e.g., cholera after floods, respiratory disease after forest fires, cancer after technological accidents), forecasting disasters and accurately assessing damage are essential in reducing negative health consequences. ${ }^{10}$ Remote sensing and space technology have a long track record in contributing to disaster management processes. For instance, remote sensing permits the near-real-time assessment of fire spread, which can be used to assess fire effects - including health effects - at a very low cost, which complements necessary field campaigns for the in situ assessment of damage and the planning of restoration measures. One might think to the 2020 US West-Coast wildfires, when satellites provided images and a wealth of complementary information needed to monitor the blazes.

But the link between disasters and health might be even more straightforward as the outbreak itself of an infectious disease can well qualify as a disaster. Just as satellites and space technology offer solutions in connectivity and inclusion in less extreme times, they are suitably placed to do this even more so in times of crisis, particularly where terrestrial communications are insufficient. Earth observation makes it possible to gather high-resolution information on a broad scale, which provides and improves opportunities to analyse and predict infectious and environmentally related diseases. For example, remote-sensing observation of air, land and ocean parameters can now be used to predict outbreaks of or trends in diseases such as meningitis, malaria and cholera. ${ }^{11}$ Communication made possible by satellites then helps to provide remote diagnosis, ${ }^{12}$ initial treatment and follow-up in particular in rural areas with limited access to health care, as well as support and training to medical personnel. ${ }^{13}$

This potential is not a recent discovery. In 1999, the Third UN Conference on the Exploration and Peaceful Uses of Outer Space (UNISPACE III) culminated in a resolution entitled 'The Space Millennium: Vienna Declaration on

\footnotetext{
9 See contributions in the 'Thematic Section' of this Yearbook.

10 See the Revised draft 'Space203o' agenda and implementation plan (21 February 2020), UN Doc A/AC.105/C.2/L.316, Overarching objective 2, paras. 2.5; 2.6.

11 Thematic Priority 5, Strengthened space cooperation and global health, Note by the Secretariat (31 October 2017), UN Doc A/AC.105/1172, para. 4O(a).

12 An example of an ESA-backed project is AMAZON, a compact device for vital-sign monitoring and remote diagnosis as part of emergency response.

132020 Scientific and Technical Subcommittee Report (n 1) para. 244.
} 
Space and Human Development', which declared that action should be taken 'to improve public health services by expanding and coordinating space-based services for telemedicine and for controlling infectious diseases.' ${ }^{14}$ To follow up on the recommendations of UNISPACE III, the COPUOS Action Team on Public Health (Action Team 6) was created in 20o1. From that moment on, although with different names - Action Team on Public Health, Action Team 6 Follow-up Initiative, Expert Group on Space and Global Health - there has always been a working group devoted to global health working with or within the Scientific and Technical Subcommittee. ${ }^{15}$ The final step forward was taken in 2018, when the copuos added a new item entitled 'Space and global health' on the agenda of its Scientific and Technical Subcommittee and established within the Scientific and Technical Subcommittee the existing Working Group on Space and Global Health. The latter submitted a questionnaire to the Member States with the purpose of establishing a set of recommendations on the basis of the responses received. ${ }^{16}$ States' views are nonetheless multifarious, in particular on the 'establishment of a dedicated platform for effective coordination among United Nations entities, other international organizations and relevant actors on space and global health issues.' ${ }^{17}$

According to the Russian Federation, it would not be appropriate to establish a dedicated platform for effective coordination among United Nations entities and other international organizations. It is the World Health Organization (wHO), as a specialized agency of the United Nations, that deals with global health issues. Accordingly, more effective use should be made of existing forums, including the already recalled Working Group on Space and Global Health. ${ }^{18}$ The EU likewise proposed to use a platform that is already under development by the Joint Research Centre of the European Commission: the Epidemic Intelligence from Open Sources platform. ${ }^{19}$ The majority of States

14 The Space Millennium: Vienna Declaration on Space and Human Development, Third United Nations Conference on the Exploration and Peaceful Uses of Outer Space (UNISPACE III), Vienna, 19 to 3 O July 1999, para. 1(b)(i).

15 For further details, see <https://www.unoosa.org/oosa/en/ourwork/copuos/stsc/gh/ index.html>.

162019 Scientific and Technical Subcommittee Report (28 February 2019), UN Doc A/AC.105/ 1202, annex III, appendix II, Questionnaire regarding policies, experiences and practices in the use of space science and technology for global health.

17 Question n. 2 of the Questionnaire. The establishment of a globally accessible platform was recommended under Thematic Priority 5 (n 11) para. 74(b).

18 Response to question n. 2 by Russia (12 November 2019), UN Doc A/AC.105/C.1/117/Add.1; in similar terms, Germany (16 November 2020), UN Doc A/AC.105/C.1/119.

19 Response to question n. 2 by the European Union (30 October 2019), UN Doc A/ AC.105/C.1/117. 
on the contrary argued that a platform should be created ex novo, ${ }^{20}$ and be eventually managed by an ad hoc secretariat. ${ }^{21}$

Formal mechanisms for inter-agency coordination and cooperation in spacerelated activities already exist within the United Nations system. For instance, the Inter-Agency Meeting on Outer Space Activities (UN-Space), under the lead of the secretariat of copuos - the Office for Outer Space Affairs ${ }^{22}$ and the Focus Group on Artificial Intelligence for Health, which was established by the wно together with the International Telecommunications Union. ${ }^{23}$ Given this situation, it may not make sense to create a further platform and a new secretariat, but to more effectively use already existing mechanisms to create synergies and regulatory efficiencies between the otherwise distinct domains of health care on one hand, and use of outer space, on the other. The first feasible steps would be to inform the wHo of the work of the Working Group on Space and Global Health, ${ }^{24}$ to strengthen institutional arrangements between the Office for Outer Space Affairs and wHo for effective collaboration, ${ }^{25}$ then to include medical experts both in the Working Group on Space and Global Health ${ }^{26}$ and in delegations to the sessions of the Scientific and Technical Subcommittee. ${ }^{27}$

A further issue is standardization and validation. As with all products, medical and health equipment require validation and certification according to recognized international standards. Existing standardization organizations such as the International Organization for Standardization, ${ }^{28}$ may and should play a role in the definition of standards applicable to space technologies used

20 Response to question n. 2 by Algeria, Philippines, Switzerland, Turkey, India, Argentina, Colombia, Peru.

21 In this sense the response to question n. 2 by Switzerland (12 November 2019), UN Doc A/AC.105/C.1/117/Add.1.

The Inter-Agency Meeting on Outer Space Activities (UN-Space) was established in the mid-1970s with the aim of promoting synergies and avoiding duplication of efforts related to the use of space technology and applications in the work of United Nations entities.

23 See the Responses to Questionnaire by the International Telecommunication Union (10 December 2020), A/AC.105/C.1/119/Add.2.

242020 Scientific and Technical Subcommittee Report ( $\mathrm{n}_{1}$ ) annex III, Report of the Working Group on Space and Global Health, para. 9.

25 Thematic priority 5 (n 11) para. 75.

26 In this sense, response to question $n .11$ by Japan (30 October 2019), UN Doc A/AC.105/ C.1/117.

$27 \quad 2020$ Report of the Working Group on Space and Global Health, (n 24), para. 10.

28 The International Organization for Standardization (ISO) is a non-governmental organization established to promote standards for international trade, communications and manufacturing. It is made up of members from the national standards bodies of 163 countries. 
for health and medical purposes. ${ }^{29}$ In order to enable users to rely on information provided to them through space-based applications, Germany proposed to explore the use of digital signatures in space-enabled health applications to validate that the information provided is from trusted sources and has not been altered..$^{30}$

In conclusion, the key goals for outer space-related governance to further public health objectives are synergy, interdisciplinary approach, and interoperability. Yet, as attractive as these key goals appear, their implementation is not an easy target to reach. Although 22 years have passed since UNISPACE III, the link between space and global health is still in its infancy. We are still at the stage of gathering information, identifying who can do what, and defining competences and the governance structure for a cooperative platform to be eventually established.

One agenda item of the Scientific and Technical Subcommittee is specifically devoted to 'space debris'. While there are some existing efforts to address this issue, new challenges remain. Several States and international organizations are implementing space debris mitigation measures consistent with the copuos Space Debris Mitigation Guidelines, ${ }^{31}$ the Inter-Agency Space Debris Coordination Committee (IADC) Space Debris Mitigation Guidelines, ${ }^{32}$ and relevant Iso standards. ${ }^{33}$ This shows that "soft regulation" does not necessarily imply "soft implementation". The development and application of new technologies, the improvement of the design of launch vehicles and spacecraft, the improvement of the protection of space systems from space debris, ongoing research related to re-entry and re-orbiting satellites, collision avoidance

29 Within Iso Technical Committee 2o, the two subcommittees developing space standards are Subcommittee 13 and Subcommittee 14. Subcommittee 13 develops international space data message standards. Subcommittee 14 develops standards that capture best practices for space systems and operations.

30 See response to question $n .3$ by Germany (n 18$)$.

31 See the copuos Space Debris Mitigation Guidelines (2007 copuos Report, UN Doc A/62/20, paras. 118-119 and Annex), and the 2019 CopUos Guidelines for the long-term sustainability of outer space activities, which also contain several rules devoted to space debris mitigation.

32 The IADC is an international governmental forum for the worldwide coordination of activities related to the issues of debris in outer space. The list of the Member Agencies is available at <https://www.iadc-home.org/>. 2020 Scientific and Technical Subcommittee Report (n 1) para. 97. 
in combination with the monitoring and modelling of space debris, and the extension of satellite lifespans will all have the effect of limiting the creation of additional space debris. ${ }^{34}$

In addition to contemplating compliance with debris mitigation measures as a requirement to carry out space activities, States could more carefully explore the option of regulatory incentives. For instance, a link could be legally established between the adoption of more stringent mitigation measures and a lower requested insurance amount. It would be also useful to develop a uniform metric for the environmental footprint of each new mission to evaluate its impact on the space environment. ${ }^{35}$

However, there are also new challenges including the increasing placement of large and mega-constellations of satellites, with the higher risk of debris they unavoidably imply, ${ }^{36}$ and problems relating to the collision of nuclearpowered space objects with space debris. ${ }^{37}$ There are many proposals to address these new challenges. Some States start from the premise that many of the orbital debris existing in outer space are the result of the past operations of major spacefaring nations. These States argue that major space faring nations including those States about to place large and mega-constellations of satellites, should accept the 'moral responsibility' of assisting less developed spacefaring nations, both technically and financially, in ensuring space debris mitigation. Otherwise, the new entrant countries would be unable to claim their right to explore and use outer space as the common province of humankind. ${ }^{38}$ To walk on the slippery slope of moral responsibility might not result in action from States. But there is merit in this reasoning that ultimately links the existing space debris issue with the freedom to explore and use outer space. A duty to preserve the sustainability of space activities is indeed inherent in Article I of the Outer Space Treaty (OST), in the sense that sustainability of space activities is a prerequisite for an enduring freedom of exploration and use of outer space. With spacecraft being at risk of catastrophic collisions even with small space debris, an increase in debris could hinder such freedom and ultimately reduce the prospects of exploring outer space. ${ }^{39}$

\footnotetext{
342020 Scientific and Technical Subcommittee Report, (n 1), paras. 100-101.

35 In this sense, Statement by the European Space Agency on Space Debris (6 February 2020).

$36 \quad 2020$ Scientific and Technical Subcommittee Report, (n 1), para. 104.

37 Replies received from Algeria (20 November 2019), UN Doc A/AC.105/C.1/116/Add.1.

38 Replies received from Pakistan (30 October 2019), UN Doc A/AC.105/C.1/116.

39 For the view that art. IX OST, supplemented by general international law rules and by the copuos Space Debris Guidelines, already provides a set of important limits and constraints for States as far as the proliferation of debris is concerned, see Diego Zannoni,
} 
Numerous studies indicate that, as space debris increases in quality and quantity, the primary source of new space debris will be from collisions, ${ }^{40}$ especially in the Low Earth and Geostationary Orbits, which are the most crowded. ${ }^{41}$ In the light of this, some delegations have adopted an approach focusing on the removal of space debris and argue that the major contributors to space debris must take appropriate responsibility in its removal under an internationally agreed framework. ${ }^{42}$ Since it is in most cases impossible to trace a fragment back to the object from which it originates, and to identify a responsible and liable State, a proposal could be renewed to establish an "International Outer Space Clean-Up Fund" aimed both at providing compensation for damage caused by unidentifiable space debris, ${ }^{43}$ and to pay the costs for their removal before that damage occurs. Each State should contribute to the Fund according to its past and actual use of the space "environment", and a useful indicator to this purpose could be the profit made, or the cost involved in launches.

As far as the use of onboard nuclear power sources is concerned, Pakistan proposed that such use should be restricted through an international legally binding agreement to only those missions that essentially require a nuclear power source. ${ }^{44}$ At present, guidelines and criteria for safe use of nuclear powers sources in outer space are exclusively contained in nonbinding instruments: GA resolution 47/68 on Principles Relevant to the Use of Nuclear Power Sources in Outer Space ${ }^{45}$ and the Safety Framework for Nuclear Power Source Applications in Outer Space, jointly published by the copuos Scientific and Technical Subcommittee and the International Atomic Energy

'Out of Sight, Out of Mind? The Proliferation of Space Debris and International Law', forthcoming.

Guideline 3 ('Limit the probability of accidental collision in orbit') of the copuos Space Debris Mitigation Guidelines.

41 Collisions between satellites will produce a number of fragments, some of which may be capable of fragmenting another object upon collision, creating even more fragments. The result would be an exponential increase in the number of objects with time, creating a self-sustaining debris belt around the Earth. This is also known as the Kessler Effect. Cf. Donald J. Kessler \& Burton G. Cour-Palais, 'Collision Frequency of Artificial Satellites: The Creation of a Debris Belt' (1978) Journal of Geophysical Research, 2637-2646.

422 2020 Scientific and Technical Subcommittee Report (n 1) para. 105.

43 In this sense, Sylvia Ospina, 'Outer Space: "Common Heritage" or "Common Junkyard" of Mankind?', (1987) Proceedings of the 3oth Colloquium on Outer Space Law, 231.

44 In this sense, Replies received from Pakistan (n 38$)$.

45 UNGA Resolution 47/68 on Principles Relevant to the Use of Nuclear Power Sources in Outer Space (14 December 1992). 
Agency. ${ }^{46}$ It is worth noting that GA resolution $47 / 68$ specifically lays down the last resort principle which is advocated by Pakistan such that: 'the use of nuclear power sources in outer space shall be restricted to those space missions which cannot be operated by non-nuclear energy sources in a reasonable way'. ${ }^{47}$ Yet, in the present international situation, the translation of such guidelines and criteria into a binding text does not seem realistic. ${ }^{48}$

The Outer Space Treaty explicitly prohibits the sole placement in orbit around the Earth of any objects carrying 'nuclear weapons', ${ }^{49}$ and of course this language does not encompass non-weaponized nuclear power sources. But other obligations contained in the Outer Space Treaty might be relevant in this context, namely the obligation to cooperate and assist (Articles I and IX Outer Space Treaty), to conduct exploration of outer space, including the Moon and other celestial bodies, so as to avoid their harmful contamination, and the obligation to undertake international consultations before proceeding with any activity which could cause harmful interference with activities of other States (Article Ix Outer Space Treaty). ${ }^{50}$

\section{The Collision of Earth with Asteroids}

The number of known near-Earth objects (NEO) had exceeded 22,212 as of 5 February $2020 .^{51}$ The main legal issue here is to clarify whether or not States are obliged to share information with regard to discovering, monitoring and physically characterizing potentially hazardous near-Earth objects in order to ensure that all nations, in particular those with limited capacity to predict and mitigate an impact of a NEO, are aware of potential collisions of an asteroid or comet with the Earth.

46 Safety Framework for Nuclear Power Source Applications in Outer Space (19 May 2009), UN Doc A/AC.105/934. As the preface of the document specifies, the Safety Framework provides voluntary guidance and is not legally binding under international law. It is not even a publication in the IAEA Safety Standards Series.

47 GA Resolution $47 / 68(\mathrm{n}$ 45) principle 3.

48 According to the US, for example, the Safety Framework satisfies the "safety intent" of the Principles Relevant to the Use of Nuclear Power Sources in Outer Space, and therefore is sufficient guidance to States and international organizations. Statement by the United States on "Use of Nuclear Power Sources in Outer Space" (5 February 2020).

49 See art. IV of the Outer Space Treaty.

50 In this sense, see further Andrea Bianchi, 'Il regime internazionale delle salvaguardie relative all'uso dell'energia nucleare nelle missioni spaziali', in Francesco Francioni, Fausto Pocar (eds) Il regime internazionale dello spazio (Giuffré 1993) 127.

$5^{1} \quad 2020$ Scientific and Technical Subcommittee Report (n 1) para. 175. 
An authoritative 2020 Report supported the view that Article XI OST applies to such a situation ${ }^{52}$ as it requires State Parties to inform others about the 'results' of their activities in outer space to the greatest extent feasible and practicable. ${ }^{53}$ Of course, Article XI OST might only apply if the information is collected through satellites, not from ground-based radars. Indeed, the activities the obligation refers to, and from which information to share is obtained, are 'in outer space. The mere fact that an asteroid comes from outer space is not sufficient to trigger the obligation to inform under Article XI OST. Given the absence of international instruments addressing this threat in a comprehensive manner, it would be necessary to assess whether or not a duty exists to notify impending natural disasters under general international law. ${ }^{54}$

In consideration of the short time that might be available to take decisions and actions at the international level in case of a NEO impact threat, a template should be drafted in advance to define the information to share and the procedure to follow with regard to the dissemination..$^{55}$ The International Asteroid Warning Network (IAWN) and the Space Mission Planning Advisory Group (SMPAG) ${ }^{56}$ are developing criteria for impact response action which could be included therein.

\section{Final Remarks}

It is now time to take stock and attempt to answer the question: where do we stand in dealing with the three issues under analysis in this paper? The answer depends on the area of space law under consideration. For disaster management and space debris mitigation, cooperation systems and guidelines already

$52 \quad$ Planetary Defence Legal Overview and Assessment Report by the Space Mission Planning Advisory Group (SMPAG), Ad-Hoc Working Group on Legal Issues to SMPAG (8 April 2020), 19; 25 .

53 The Report correctly underlines that Art. 5 para. 3 of the Moon Agreement is applicable to potential collisions of an asteroid or comet with the Earth, even if at the same time admits that the legal relevance of this provision is limited by the fact that few space-faring nations are parties to the Moon Agreement. Ibid, 19.

54 On this issue, see Diego Zannoni, Disaster Management and International Space Law (Brill 2019) 40-47.

55 Planetary Defence Legal Overview and Assessment Report (n $\left.5^{2}\right) 26$.

$5^{6}$ SMPAG currently has 19 members and 6 permanent observers, with the European Space Agency serving as the Chair and the Office for Outer Space Affairs serving as the secretariat. There are currently 25 signatories to the IAwn Statement of Intent from all over the world, which signatories have a variety of assets for discovering and observing near-Earth objects. IAWN is coordinated by the Planetary Defense Coordination Office of NASA. 
exist. For management of pandemics and planetary defence, we are still at the stage of gathering information and identifying who can do what. What appears clear from the above is that the sophisticated and intricate web of committees, sub-committees, working groups, principles, rules, guidelines, standards, and reports will only be able to make a small contribution without a change of mentality and habits penetrating through all layers of society and without a real intention to act against global challenges. 